International Journal of Current Microbiology and Applied Sciences

ISSN: 2319-7706 Volume 9 Number 2 (2020)

Journal homepage: http://www.ijcmas.com

Original Research Article

https://doi.org/10.20546/ijcmas.2020.902.295

\title{
Gas Chromatography Study of Methanolic Leave Extract of Moringa oleifera Lam.
}

\author{
Nishu $^{1 *}$, Chandrawati Jee ${ }^{1}$ and Ravi Kumar ${ }^{2}$ \\ ${ }^{1}$ Department of Biotechnology, A.N. College, Patna, Magadh University, \\ Bodh Gaya-824234, Bihar, India \\ ${ }^{2}$ Department of Horticulture (Vegetable and Floriculture), Bihar Agricultural University, \\ Sabour-813210, Bhagalpur, Bihar, India
}

*Corresponding author

\section{Keywords}

GC-MS analysis,

Methanol leaf

extract, Moringa

oliefera

Article Info

Accepted:

18 January 2020

Available Online:

10 February 2020

\section{A B S T R A C T}

The present study was done to investigate bioactive compound present in methanolic leaf extract of Moringa oliefera through Gas ChromatographyMass Spectrum (GC-MS). The results of the GC-MS analysis revealed the presence of 15 compounds with peak percentage in chromatogram. The major compounds found were n-Hexadecanoic acid (31.82), cis-Vaccenic acid (27.21), 3-Chloro-N-isochroman-1-ylmethyl-propionamide (7.21). The maximum peak area \% of 31.82 with retention time 18.62 min was recorded in n-Hexadecanoic acid. The minimum peak area of 1.0 with retention time 23.94 min was recorded in beta.-1-Rhamnofuranoside, thiooctyl. Hence, result shows that $M$. oliefera contains enormous bioactive compounds which have various biological activities. Therefore, it is recommended that newer Moringa extract based modern drug to be formulated and produce on commercial scale.

\section{Introduction}

Nature has been great source of medicinal curatives for thousands of years and an impressive number of modern drugs have been isolated from natural sources. These isolations-based drugs were used in traditional medicines. Medicinal plants are of great importance to the health of human being. About 3.4 billion people in the developing world depend on plant-based traditional medicine. There is a need to validate the ethnomedicinal use of herbal medicine and subsequently isolate and characterize the compounds which are likely to be added to the potential list of drugs (Okigbo et al., 2008). Over the last few decades, exploration of herbal drugs use has been increased due to their easy availability, therapeutic potential, least side effects and low cost. At present 
nearly $80 \%$ of the world populations rely on herbal drugs for their health care need (Sermakkani et al., 2012). Gas Chromatography Mass Spectroscopy is instrument used to detect compound which are present in very trace amount in extract. It is best technique to identify bioactive compounds of long chain hydrocarbon, alcohols, acids, esters, alkaloids, steroids, amino acids and nitro compounds etc. The unknown organic compounds in a complex mixture can be determined by interpretation and also by matching the spectra with reference spectra (Balamurugan et al., 2015). Moringa oleifera is the most widely cultivated species of the Moringa of family Moringaceae. Common names of this plant are Horseradish, Drumstick, Mothers best friend, Sahjan. Moringa is a fast growing, evergreen or deciduous that can grow up to height of $8 \mathrm{~m}$ to $12 \mathrm{~m}$. Its trunk diameter grows up to $1.5 \mathrm{ft}$. It can be grown in severe drought and mild frost conditions and hence widely cultivated across the world especially in tropical and subtropical areas. Its young seed pods and leaves are used as vegetables (Fuglie, 1999). Different parts of this plant are being employed for the treatment of different ailments in the indigenous system of medicine. The plant is reported to be used in phytomedicine as antioxidant, antimicrobial, anti-inflammatory, antipyretic, antiulcer, antidiabetic, anti-tumor and as a hypocholesteromic agent (Ijioma et al., 2014). The aim of present study is to investigate phytochemical present in methanolic leaf extract and identification and characterization of bioactive by using GC-MS analysis.

\section{Materials and Methods}

\section{Collection of plant material:}

The Moringa oliefera fresh leaves were collected from botanical garden of A.N. College, Boring road, Patna district, Bihar,
India. The plant leaves were identified by Prof. Chandramohan singh at the Taxonomy section of Botany Department of A.N.College, Patna. The plant material was thoroughly washed in running water, air dried under shade and pulverized to powder using mechanical grinder.

\section{Preparation of Extract:}

The leaf powder (50 g) was dissolved in $500 \mathrm{ml}$ of Methanol solvent for extraction using Soxhlet apparatus for $24 \mathrm{hrs}$. The temperature was between $60^{\circ} \mathrm{C}$ to $65^{\circ} \mathrm{C}$. The solvent was evaporated by rotary vacuum evaporator to yield a semi solid mass of 5.46 g. The semi-solid extract stored in refrigerator at $4^{0} \mathrm{C}$, and used in GC-MS analysis.

\section{GC-MS (Gas chromatography- Mass Spectrometry) analysis:}

The GC - MS analysis was carried out using a Varian 225 - Gas Chromatograph coupled to a mass detector, Turbo mass gold - Varian spectrometer with an Elite- (100\% Dimethyl poly siloxane), $30 \mathrm{~m} \times 0.25 \mathrm{~mm}$ ID x $0.25 \mu \mathrm{m}$ of capillary column. Injection temperature was maintained at $250{ }^{\circ} \mathrm{C}$, Helium flow rate as $1.5 \mathrm{ml} / \mathrm{min}$ and ion source temperature at $230{ }^{\circ} \mathrm{C}$. Injection was performed in the split less mode and the volume was $1 \mu \mathrm{L}$. The instrument was set to an initial temperature of $70^{\circ} \mathrm{C}$, and maintained at this temperature for 3 min. At the end of this period the oven temperature was arisen up to $300^{\circ} \mathrm{C}$, at the rate of an increase of $10^{\circ} \mathrm{C} / \mathrm{min}$, and maintained for $9 \mathrm{~min}$. The mass spectra of compounds in samples were obtained by electron ionization (EI) at $70 \mathrm{eV}$, and the detector operated in scan mode from $40-700$ $\mathrm{m} / \mathrm{z}$. The MS start time was $3 \mathrm{~min}$; end time was 35 min with solvent cut time was about 3 min. The relative percentage amount of each component was calculated by comparing its average peak area to the total areas. 


\section{Identification of phytochemical components}

Identifications of compounds were based on mass spectral matching with standard compounds in National Institute of Standard and Technology (NIST) having more than 62000 patterns. The essential chemical constituents were identified by matching mass spectra with spectra of reference compounds in mass spectral library of the National Institute of Standards and Technology (NIST 11). The relative amounts of individual components were expressed as percent peak areas relative to the total peak area.

\section{Results and Discussion}

The results of the GC-MS analysis of the methanolic extract of the leaf of M.oleifera reveals the presences of 15 phytochemical which are shown in Figure 1. The various bioactive compounds of the Methanolic extract were identified by GC-MS technique were listed in Table 1. The major components with retention time are n-Hexadecanoic acid (18.62), 1,2,3-Cyclopentanetriol (13.03), Tetradecanoic acid(2.18), Octadecanoic acid (20.52), cis-Vaccenic acid (20.35), 3-Chloro$\mathrm{N}$-isochroman-1-ylmethyl-propionamide (23.36). Maximum 31.82 peak area \% was recorded for fatty acid \& minimum 1.0 peak area \% was recorded for glycoside. The retention time for steroids were 29.16 and 29.26 recorded. The maximum 13.03 retention time was recorded for fatty acid ester. GC-MS result analysis includes the active principles with their retention time, peak area and nature of compounds in the methanol extracts of leaf of Moringa oliefera. The GC-MS spectrum confirmed the presence of various components with different retention times as illustrated in Figure 1. The GC-MS analysis study of the methanolic leaf extract of
Moringa oliefera had shown the presence of lots of phytochemicals having medicinal bioactive compound, strengths contribution to develop new drug.

The Various phytochemical compounds identified in this study have great biological potential and can be used in pharmaceutical product. Now a day's use of herbal medicine is increasing due to elevation in scientific research and awareness of bioactive compounds obtained from plants for medicinal use. Similar study by Rukshana (2017), the GC-MS analysis of Pergularia daemia leaves reveals the presence of seventeen compounds. GC-MS analysis resultof the bioactive compounds of leaves ethanolic extract of the Psidium guajava indicated the existence of Alpha - bisabolol, 1, 2- Benzene dicarboxylic acid, buty, Hexadeca-2, 6, 10, 14-tetraen, Caryophyllene, Bis (2-ethylhexyl) phthalate, Nerolidol and Germacrene (Thenmozhi et al., 2015). 18 compounds identified by LC/MS of moringa, two compounds, i.e. isoquercetin and cryptochlorogenic acid, were well known for their anti-inflammatory and antioxidant activity (Sudha et al., 2010). Aja et al., on GC/MS analysis of Moringa oleifera leaf and seed which revealed that 9 - octadecenoic acid (20.89\%) constitutes the major constituent of the leaf extract while oleic acid (84\%) is the major component of the seed extract. 15 compounds have been identified from the ethanol extract of leaf and 16 from bark of Moringa concanensis by GC - MS analysis by Balamurugan, et.al., 2015. The main compounds were methyl (11E)-11octadecanoate, $30.15 \%$ and cis octadecanoic acid, $19.16 \%$ with bioactivities of antimetabolic syndrome and anticardiovascular risk factor acting by decreasing cholesterol and triglyceride (Gillingham et al., 2011). 
Table.1 GC- MS analysis of Moringa oliefera leaves extract

\begin{tabular}{|c|c|c|c|c|}
\hline Sl.No. & $\begin{array}{c}\text { Retention } \\
\text { Time (Min) }\end{array}$ & Name of the Compound & $\begin{array}{c}\text { Peak } \\
\text { Area } \mathbf{( \% )}\end{array}$ & Nature of Compound \\
\hline $\mathbf{1 .}$ & 13.03 & 1,2,3-Cyclopentanetriol & 1.68 & Fatty acid ester \\
\hline $\mathbf{2 .}$ & 15.28 & L-Galactose, 6-deoxy- & 4.94 & Sugar \\
\hline $\mathbf{3 .}$ & 18.62 & n-Hexadecanoic acid & 31.82 & Saturated Fatty Acid \\
\hline $\mathbf{4 .}$ & 18.67 & Tetradecanoic acid & 2.18 & Saturated Fatty Acid \\
\hline $\mathbf{5 .}$ & 20.35 & cis-Vaccenic acid & 27.21 & Fatty Acid \\
\hline $\mathbf{6 .}$ & 20.52 & Octadecanoic acid & 4.82 & Fatty Acid \\
\hline $\mathbf{7 .}$ & 21.62 & Palmitoyl chloride & 1.51 & Fatty Acid Chloride \\
\hline $\mathbf{8 .}$ & 23.36 & $\begin{array}{c}\text { 3-Chloro-N-isochroman-1- } \\
\text { ylmethyl- propionamide }\end{array}$ & 7.21 & Amide \\
\hline $\mathbf{9 .}$ & 23.46 & $\begin{array}{c}\text { 2-Butenoic acid, 2-methoxy-3- } \\
\text { methyl-, methyl ester }\end{array}$ & 1.70 & Ester \\
\hline $\mathbf{1 0 .}$ & 23.67 & 3,4-Dichlorobenzonitrile & 2.28 & Aromatic Compound \\
\hline $\mathbf{1 1}$ & 23.90 & $\begin{array}{c}\text { Mannitol,1,4-di-O-methyl- } \\
\text { tetraacetate }\end{array}$ & 1.72 & Alcohal ester \\
\hline $\mathbf{1 2 .}$ & 23.94 & $\begin{array}{c}\text { beta--1-Rhamnofuranoside, } \\
\text { thio-octyl- }\end{array}$ & 1.0 & Glycoside \\
\hline $\mathbf{1 3 .}$ & 27.85 & Vitamin E & 2.24 & Alcoholic Compound \\
\hline $\mathbf{1 4}$ & 29.16 & gamma-Sitosterol & 2.82 & Steroid \\
\hline $\mathbf{1 5}$ & 29.26 & Pregn-5,7-diene-3-ol-20-one & 1.42 & Steroid \\
\hline
\end{tabular}

Fig.1 Chromatogram obtained from the GC-MS with the extract of Moringa oleifera leaves

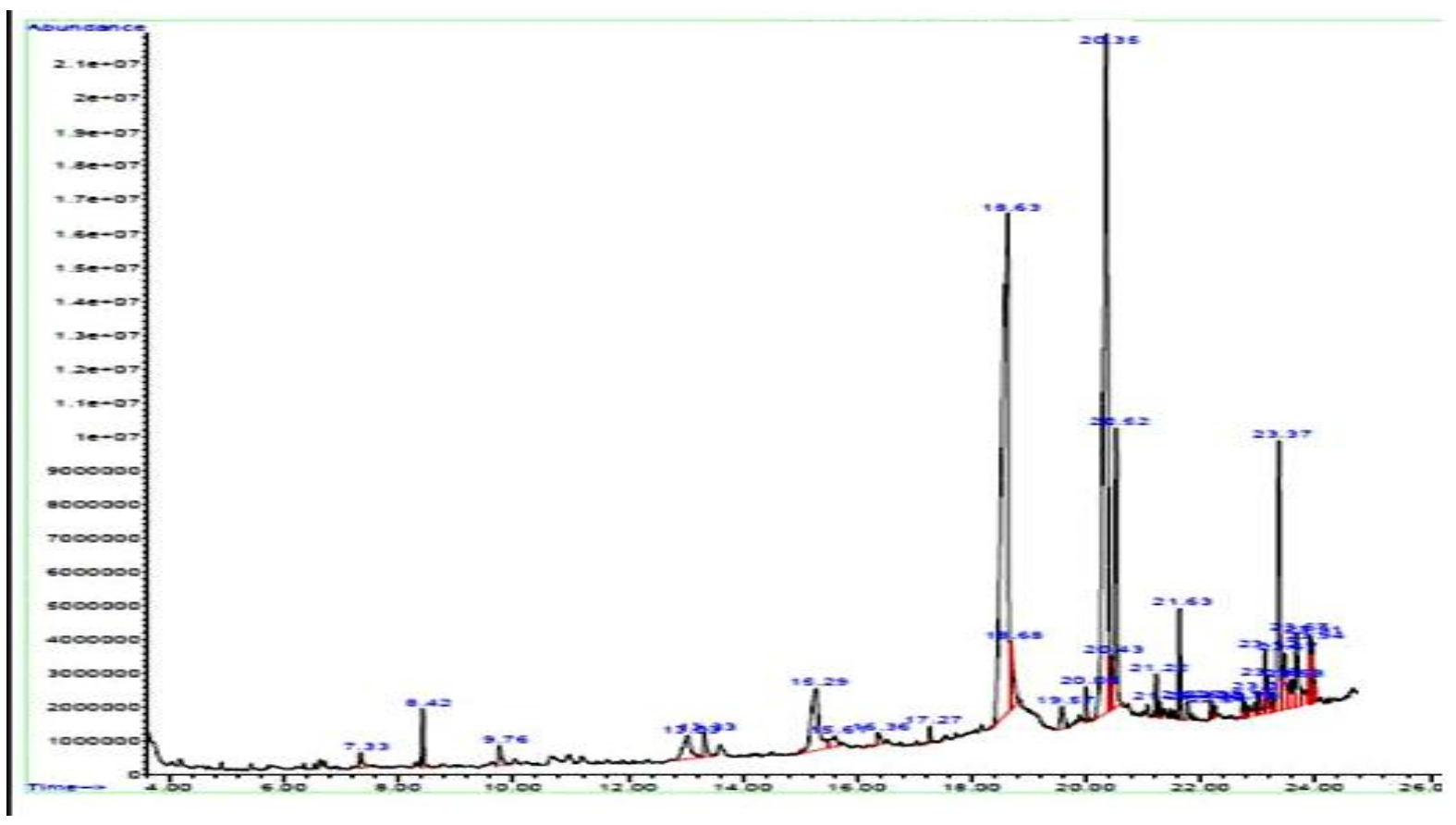


From GC-MS result Moringa oleifera contains octadecanoic acid (stearic acid) $\mathrm{C}_{18} \mathrm{H}_{36} \mathrm{O}_{2}$ and cis octadecenoic acid (cis oleic acid) $\mathrm{C}_{18} \mathrm{H}_{34} \mathrm{O}_{2}$ which had hypolipidemic activity may be because it contains 5-alpha reductase inhibitor which may have blocked HMG-CoA reductase which is a major enzyme in the cholesterol biosynthetic pathway (Gapalakrishnan and Vadivel 2011). Hemalatha et.al., (2016) studied phytochemical composition, GC-MS analysis, in vitro antioxidant and antibacterial potential of clove flower bud (Eugenia caryophyllus) methanolic extract. GC-MS results indicate the presence of aromatic compounds and major constituents were found to be eugenol and eugenyl acetate.

Hence concluded, from the GC-MS analysis of Moringa oleifera leaf extract shows various bioactive compounds with therapeutic potentials. The presence of bioactive compounds in the leaf of this plant becomes scientific base for the use as medicine in various alignments. The present study was conducted to identifying the nature of the components responsible for their antibacterial and antioxidant activity. This study clearly shows that GC-MS is a very important technique for isolation and characterization of bioactive metabolites. Further research is required to identify the role of bioactive compounds in antibacterial and antioxidant.

\section{Acknowledgment}

The authors are thankful to Prof. Dr. Chandramohan Singh, Department of Botany, A. N. College. Patna, Bihar and technicians of ITS laboratory, New Delhi for their help, support for successful completion of the work.

\section{References}

Aja, P. M., Nwachukwu, N., Ibiam, U. A.,
Igwenyi, I. O., Offor, C. E., and Orji, U. O. (2014). Chemical constituents of Moringa oleifera leaves and seeds from Abakaliki, Nigeria. Am J Phytomedicine Clin Ther, 2, 310-321

Fahey JW, Zalcmann AT, Talalay P. The chemical diversity and distribution of glucosinolates and isothiocyanates among plants. Phytochemistry 2001; 56: 5-51

Fuglie., L.J. (1999): The miracle tree: Moringa oleifera: natural nutrition for the tropics. Church world service, dakar. 68 pp.; revised in 2001 and published as the miracle tree: the multiple attributes of Moringa, 172

Gillingham, L., Dietary monounsaturated fatty acid are protective against metabolic syndrome and cardiovascular disease risk factors. Lipids. (46), 2011,209 - 228.

Gopalakrishnan, S (2011). GC - MS analysis of some bioactive constituents of Mussaenda frondosa linn. International Journal of Pharma and Bio Sciences, 2(1), 2011, 313 - 320

Hemalatha, R., Nivetha, P., Mohanapriya, C., Sharmila, G., Muthukumaran, C., \& Gopinath, M. (2016): Phytochemical composition, GC-MS analysis, in vitro antioxidant and antibacterial potential of clove flower bud (Eugenia caryophyllus) methanolic extract; $J$ Food Sci Technol, 53(2): 1189-1198

Ijioma S.N., Nwosu O.C. and Onyenegecha C., Anticholinegic property of ethanol extract of Moriaga oleifera leaves: An in vivo and in vitro approach. Journal of Clinical and Experimental Research, 2 (2), 2014, 131-135.

Iqbal, S.; Bhanger, M. I. Effect of season and production location on anti oxidant activity of Moringa oleifera leaves grown in Pakistan. J. of Food Comp. and Anal. 2006; 19: 544551. 4

Mehta, L.K., Balaraman, R., Amin, A.H., 
Baffa, P.A. and Gulati, O.D. Effects of fruits of $M$. oleifera on the li-pid profile of normal and hypercholesterolaemic rabbits. $J$. Ethnopharmacol. 2003; 86: 191 - 195

Okigbo, R.N., Mmeka, E. C. (2008): Antimicrobial effects of three tropical plant extracts on Staphylococcus aureus, Escherichia coli and Candida albicans.; Afri. J. Compl. Alter. Med.: 5 (3): 226-229.

Rukshana, M.S., Doss, A. and Kumari P.R.T.P. (2017): Phytochemical Screening and GC-MS Analysis of Leaf Extract of Pergulari adaemia (Forssk) Chiov. Asian Journal of Plant Science and Research, 7(1):915.

Sermakkani, M., and Thangapandian, V. (2012): GCMS analysis of Cassia italica leaf methanol extract, Asian
J.Pharm.Clin.Res.,:5(2), 90-94.

Sudha P, Asdaq SMB, Dhamingi SS and Chandrakala GK: Immuno modulatory activity of methanolic leaf extract of moringa oleifera in animals. Indian Journal of Physiology and Pharmacology 2010; 54: 133-140.

Thenmozhi, S. and Rajan, S. (2015): GC-MS analysis of bioactive compounds in Psidium guajava leaves. Journal of Pharmacognosy and Phytochemistry, 3(5): 162-166.

Vadivel Balamurugan, Veluchamy Balakrishnan, Arjunan Sundaresan. (2015). GC-MS analysis of leaf and Bark Extract of Moringa concanensis Nimmo, a siddha medicinal plant of South India. European Journal of Biotechnology and Bioscience. 3(12): 57-61.

\section{How to cite this article:}

Nishu, Chandrawati Jee and Ravi Kumar. 2020. Gas Chromatography Study of Methanolic Leave Extract of Moringa oleifera Lam.. Int.J.Curr.Microbiol.App.Sci. 9(02): 2590-2595. doi: https://doi.org/10.20546/ijcmas.2020.902.295 